\title{
A combined simulation of high speed train permanent magnet traction system using dynamic reluctance mesh model and Simulink"
}

\author{
Xiao-yan HUANG ${ }^{1}$, Jian-cheng ZHANG ${ }^{1}$, Chuan-ming $\mathrm{SUN}^{2}$, \\ Zhang-wen HUANG ${ }^{1}$, Qin-fen $\mathrm{LU}^{\dagger * 1}$, You-tong $\mathrm{FANG}^{1}$, Li YAO ${ }^{3}$ \\ ( ${ }^{1}$ School of Electrical Engineering, Zhejiang University, Hangzhou 310027, China) \\ $\left({ }^{2}\right.$ CSR Qingdao Sifang Co. Ltd., Qingdao 266111, China) \\ $\left({ }^{3}\right.$ Danfoss (Tianjin) Ltd., Tianjin 301700, China) \\ †E-mail: luqinfen@zju.edu.cn
}

Received Sept. 22, 2014; Revision accepted Apr. 7, 2015; Crosschecked July 20, 2015

\begin{abstract}
This paper presents a combined dynamic parameter model (DPM) of a high speed train permanent magnet traction system using a dynamic reluctance mesh model and MATLAB Simulink. First, the dynamic reluctance model of the permanent magnet synchronous motor is introduced. Then the combined models of the traction system under $i_{d}=0$ and maximum torque per ampere control are built. Simulations using both constant parameter models and DPM models are carried out. The speed and torque characteristics are obtained. The results confirm that the DPM model provides higher accuracy without much sacrifice of time consumption or computation resource.
\end{abstract}

Key words: Permanent magnet traction system, Dynamic reluctance mesh model, Dynamic parameter model (DPM), High speed train, Maximum torque per ampere control doi: 10.1631 jzus.A1400284

Document code: A

CLC number: TM922.71

\section{Introduction}

Permanent magnet (PM) motor traction systems for high speed railways have been highlighted recently due to their inherent advantages in terms of compact structure, high efficiency, and high power factor (Matsuoka, 2007). Some prototype trains have been independently developed by Alstom, Bombardier, and Siemens. Although large-scale commercial application is not in prospect at the moment, the PM motor traction system is considered as one of the

\footnotetext{
\# Corresponding author

* Project supported by the National Natural Science Foundation of China (Nos. 51177144 and 51477149), the National High-Tech R\&D Program (863 Program) of China (No. 2011AA11A101), the Qianjiang Talent Program (No. 2013R10031), and the Fundamental Research Funds for the Central Universities (No. 2014QNA4012), China

(7) ORCID: Xiao-yan HUANG, http://orcid.org/0000-0001-5185-9040

(C) Zhejiang University and Springer-Verlag Berlin Heidelberg 2015
}

most advanced high speed train technologies for the future (Mermet-Guyennet, 2010; Lee, 2012).

A common way to evaluate the performance of the PM motor traction system is a dynamic simulation using the MATLAB Simulink models (Lu et al., 2011). However, the PM motor Simulink model is based on constant machine parameters such as resistance, $d$-axis inductance $\left(L_{d}\right), q$-axis inductance $\left(L_{q}\right)$ but, in practice, the parameters such as $L_{d}$ and $L_{q}$ vary during operation. Therefore, the PM motor Simulink model cannot represent the real situation.

The finite element PM motor model can be used together with the Simulink power electronics model for accurate and complete solutions for detailed behavior (Ugalde et al., 2009). However, a substantial amount of computational resources and much longer computational time are needed, especially for the traction motor which is normally rated at a few hundred kilowatts. 
The dynamic mesh modeling (DRM) method was developed by Carpenter (1968), Ostovic (1986; 1988; 1989), Sewell et al. (1999), and Yao (2006). It is based on the reluctance mesh. The magnetic field behavior is mapped onto an equivalent lumped equivalent circuit. This DRM method can save computation time without compromising accuracy (Dogan et al., 2013; Araujo et al., 2014; NguyenXuan et al., 2014). Therefore, in this paper, a dynamic mesh PM motor model is built and combined with Simulink power electronics models for better accuracy and higher simulation efficiency.

\section{Dynamic reluctance mesh model}

\subsection{Principle of basic reluctance mesh (RM) model}

The DRM method is based on the concept of equivalent magnetic circuits. Many laws and analysis methods for magnetic circuits can be analogous to those of electric circuit theory. In electric circuits, the fundamental parameters are voltage $(V)$, current $(I)$, and resistance $\left(R_{\mathrm{e}}\right)$, and their behavior is described by network constraints, such as Kirkhoff's voltage and current laws, and their constitutive relationships are described by, for example, Ohm's law. In magnetic circuits, the corresponding fundamental parameters are magnetomotive (MMF), flux $(\Phi)$, and reluctance $\left(R_{\mathrm{m}}\right)$ as shown in Table 1. A simplified RM motor model consists of nine components as shown in Fig. 1, where the square components represent the reluctance while the circle component represents the MMF.

Table 1 Fundamental parameters in magnetic and electric circuits

\begin{tabular}{cccc}
\hline \multirow{2}{*}{$\begin{array}{c}\text { Magnetic } \\
\text { circuit }\end{array}$} & Reluctance & $\mathrm{MMF}$ & Flux \\
\cline { 2 - 4 } & $R_{\mathrm{m}}$ & $\mathrm{MMF}=\Phi \cdot R_{\mathrm{m}}$ & $\Phi=\mathrm{MMF} / R_{\mathrm{m}}$ \\
\hline \multirow{2}{*}{$\begin{array}{c}\text { Electric } \\
\text { circuit }\end{array}$} & Resistance & Voltage & Current \\
\cline { 2 - 4 } & $R_{\mathrm{e}}$ & $V=I R_{\mathrm{e}}$ & $I=V / R_{\mathrm{e}}$ \\
\hline
\end{tabular}

The magnetic circuit laws are analogous to those of electric circuits as follows: Kirkhoff's current and voltage law for magnetic circuits, for each node,

$$
\sum_{k} \phi_{k}=0
$$

$$
\sum_{k} F_{k}=0
$$

where $\phi_{k}$ is the flux and $F_{k}$ is the MMF.

The reluctance of each component can be calculated by

$$
R_{\mathrm{m}}=\frac{l}{\mu A}
$$

where $l$ is the length, $A$ is the cross section area of each component, and $\mu$ is the permeability.

Based upon the above equations, the performance of the machine can be investigated.

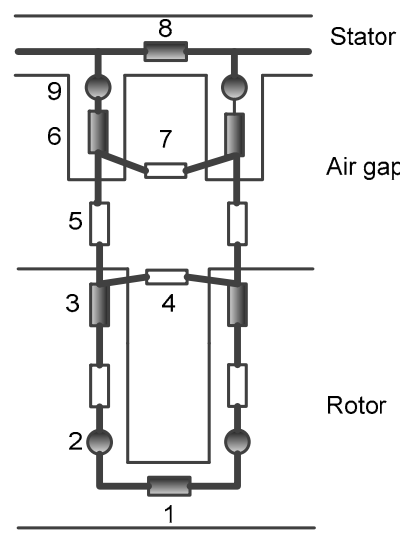

Fig. 1 Simplified RM model

1: rotor yoke; 2: magnetic source in rotor (permanent magnet); 3: rotor pole; 4: leakage between rotor poles; 5: air gap between stator and rotor; 6: stator teeth; 7: air gap between stator teeth; 8: stator yoke; 9: magnetic source in stator

\subsection{Dynamic reluctance mesh model}

The air gap plays a very important role in performance of the PM motor, because its reluctance is large compared to that of the other parts. Therefore, the air gap model is a key factor in simulating electrical machine performance accurately. However, air gap reluctances change as the rotor rotates, because under different rotor positions, the coupling between stator and rotor teeth is different.

In this study, the air gap reluctance is recalculated at every instantaneous rotor position. This is also the reason why the reluctance mesh is "dynamic". The torque can be calculated from the derivatives of the energy (co-energy) versus the displacement of the rotor. Since the air gap is the only parameter that 
varies with the rotor position, the torque can be written as (Yao, 2006)

$$
T_{\mathrm{e}}=\sum_{i=0}^{N-1}\left(\frac{1}{2} \frac{B_{i}^{2} d_{i} l_{i}}{\mu_{0}} \frac{\partial w_{i}}{\partial \theta}\right),
$$

where $B_{i}$ is the flux density in the $i$ th air gap reluctance, $\mu_{0}$ is the permeability of the vacuum, $\theta$ is the angle, $N$ is the turn number of the winding, and $d_{i}, l_{i}$, $w_{i}$ are the depth, length, width of the $i$ th air gap reluctance, respectively.

\subsection{DRM model of the PM traction motor}

A quarter model of the PM traction motor analyzed in this study is shown in Fig. 2. The interior PM rotor structure is used to improve the torque performance of the traction motor. However, due to the complex rotor structure, the magnetic calculation will be more challenging, especially in the calculation of $L_{d}$ and $L_{q}$. Based on the analysis above, the reluctance network model per pole pair is built as shown in Fig. 3 . In addition, the equivalent magnetic network model of the air gap at a certain rotor position is shown in Fig. 4, which should be changed as the rotor rotates as discussed above.

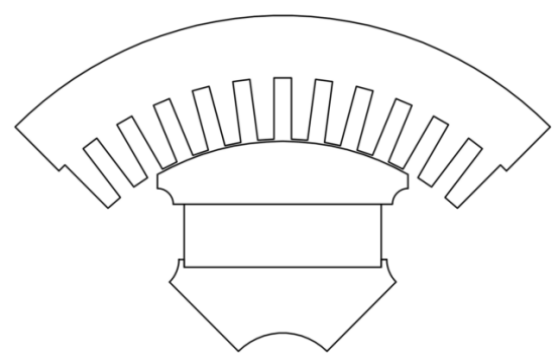

Fig. 2 Quarter model of the PM traction motor

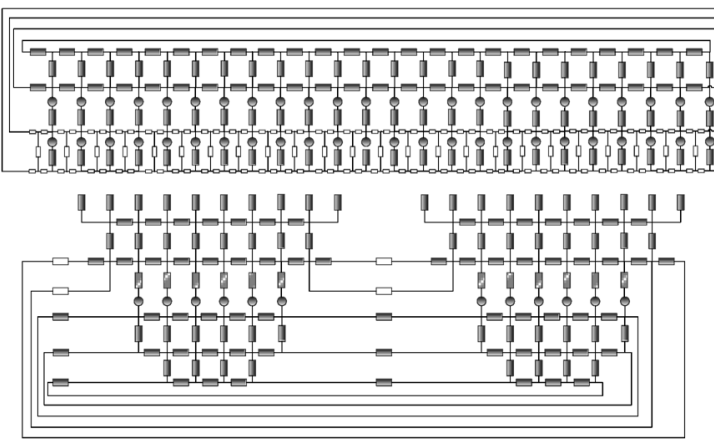

Fig. 3 Reluctance network model of the PM motor

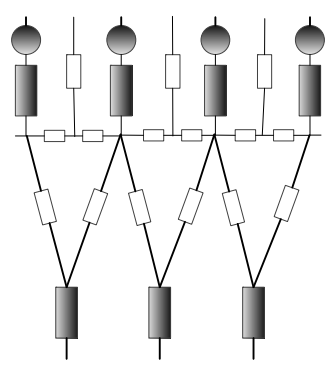

Fig. 4 Equivalent magnetic network model of the air gap

\subsection{Simulation results of DRM model}

Using the DRM model, the main motor parameters such as electromotive force (EMF) at no-load conditions, $L_{d}$ and $L_{q}$ can be accurately calculated in less time.

The back EMF at the no-load condition is calculated by Eq. (5). Based on the winding distribution, the phase- $A$ winding is across a number $k$ of stator teeth, so the flux linkage of phase- $A$ winding can be expressed as Eq. (6). The comparison results for the back EMF separately calculated by DRM and finite element method (FEM) are presented in Fig. 5. It can be seen that the result calculated by DRM has a good agreement with that calculated by FEM.

$$
\begin{aligned}
& E_{A}=-\frac{\mathrm{d} \Phi_{A}}{\mathrm{~d} t}, \\
& \Phi_{A}=\sum_{i=1}^{k} N \cdot \varphi_{i},
\end{aligned}
$$

where $E_{A}$ is the back EMF at the no-load condition of phase- $A$ winding, $\Phi_{A}$ is the flux linkage of phase- $A$ winding, and $\varphi_{i}$ is the flux through stator tooth $i$.

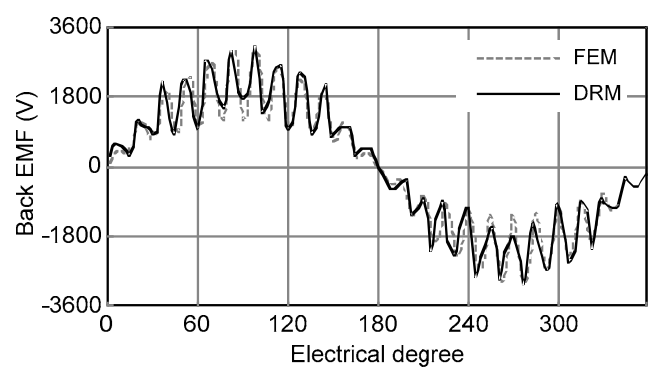

Fig. 5 Back EMF results calculated by DRM and FEM

As for calculation of $L_{d}$ and $L_{q}$, an advanced method called frozen permeability is used to consider the effect of saturation caused by magnets and current. 
The frozen permeability method calculates the inductance through two calculations. In the first calculation, excitation sources of both the winding current and the magnet are active. The resulting permeability distribution from the first calculation is used in the second calculation. In addition, in the second calculation, the magnet is set to inactive, so only the winding current is involved. Thus, the inductance can be calculated through Eq. (7). The inductance calculation results are presented in Fig. 6, and show good agreement with the FEM calculation.

$$
L=\frac{\mathrm{d} \psi}{\mathrm{d} I}
$$

where $L$ is the inductance, and $\psi$ is the flux linkage.
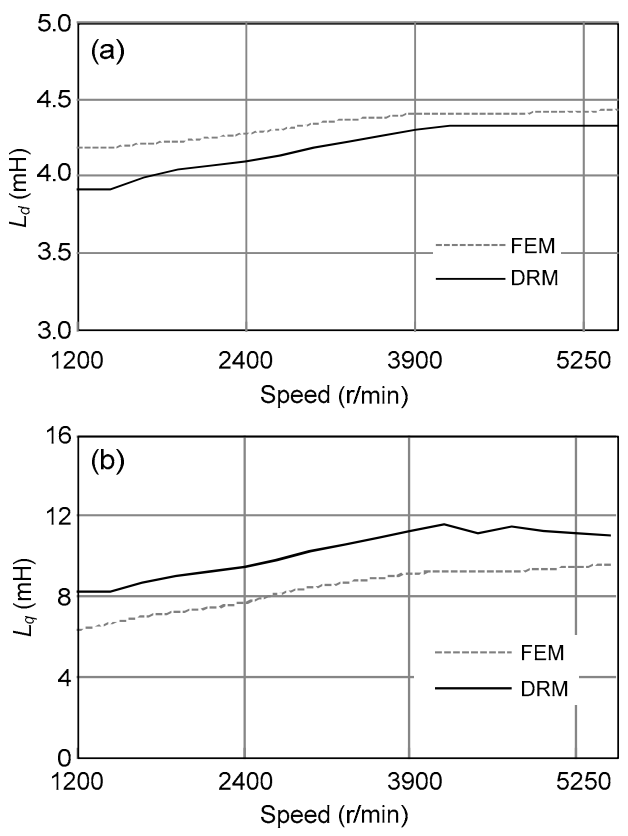

Fig. $6 L_{d}$ (a) and $L_{q}$ (b) calculated by DRM and FEM

\section{Combined model using DRM and Simulink}

The basic concept of the combined SimulinkDRM simulation is using the DRM model as the motor model, while using the control system model provided by Simulink. There are two common ways to implement the combined Simulink-DRM simulation:

1. Replacing the DRM of PM motors for the constant parameter model (CPM) of PM motors provided by Simulink. DRM and Simulink will be running simultaneously. The dynamic parameters will be provided by DRM. However, for every time-stepping, the DRM and Simulink models need iteration calculation, which makes the simulation more complicated and time-consuming.

2. A dynamic parameters database is generated using DRM simulation. Then the dynamic parameters are put in the CPM in Simulink using the database index or lookup table. In this case the constant parameters in the traditional Simulink model will be modified instantaneously according to the motor operating condition. Compared to the first method, this method is more efficient without sacrifice of accuracy. Therefore, it will be adopted in this study.

The combined simulation carried out in this paper is based on the following assumptions:

1. Ignoring the effect of rotor skew on the stator back-EMF harmonics;

2. Keeping the excitation from the PM constant;

3. Ignoring the saturation of stator end winding flux leakage.

\subsection{Dynamic modeling and interface}

The dynamic parameter permanent magnet synchronous motor (PMSM) model was built using the Simulink S-function block, to replace the traditional CPM. The following equations are used with the S-function block to build the $d-q$ coordinated PMSM model (Wang, 2011):

$$
\begin{aligned}
& \left\{\begin{array}{l}
u_{d}=R_{1} i_{d}-\omega \psi_{d}+\frac{\mathrm{d} \psi_{d}}{\mathrm{~d} t}, \\
u_{q}=R_{1} i_{q}-\omega \psi_{q}+\frac{\mathrm{d} \psi_{q}}{\mathrm{~d} t},
\end{array}\right. \\
& \left\{\begin{array}{l}
\psi_{d}=L_{d} i_{d}+\psi_{\mathrm{m}}, \\
\psi_{q}=L_{q} i_{q},
\end{array}\right. \\
& \frac{\mathrm{d} \omega}{\mathrm{d} t}=\frac{1}{J}\left(T_{\mathrm{e}}-T_{\mathrm{f}}-F \omega-T_{\mathrm{m}}\right), \\
& T_{\mathrm{e}}=\frac{3}{2} p\left[\psi_{\mathrm{m}} i_{q}+\left(L_{d}-L_{q}\right) i_{d} i_{q}\right],
\end{aligned}
$$

where $u_{d}, u_{q}$ are the voltage of the $d$-, $q$-axis; $i_{d}, i_{q}$ are the current of the $d$-, $q$-axis; $\psi_{d}, \psi_{q}, \psi_{\mathrm{m}}$ are the flux linkage of the $d$-, $q$-axis, and permanent magnet flux linkage; $T_{\mathrm{e}}, T_{\mathrm{f}}, T_{\mathrm{m}}$ are the electric torque, friction torque, and load torque; $J, F$ are the inertia, friction; $L_{d}, L_{q}$ are the inductance of the $d$-, $q$-axis, respectively, and $\omega$ is the angular speed. In dynamic parameter models, $L_{d}, L_{q}$ vary with the rotor position. 


\subsection{Vector control system}

The basic concept of PMSM vector control is to control the PMSM like a separately excited DC motor. The stator current can be defined in the $d$ - $q$ coordinate system. The field flux linkage component of the current is normally aligned with the $d$-axis while the torque component of the current is aligned along the $q$-axis. By controlling $i_{d}$ and $i_{q}$, the field and torque can be controlled respectively. In this study, the traction system behavior under $i_{d}=0$ and maximum torque per ampere control (MTPA) will be investigated.

\section{PMSM with $i_{d}=0$ control}

According to Eq. (11), when $i_{d}=0$, the torque will be determined by controlling $i_{q}$. In the case of $i_{d}=0$, there is no reluctance torque, which means it is more suitable for a non-saliency motor. In this study, the salient PMSM will be used. Thus, this method is not the best choice and is only be used here to provide comparison with other methods.

\section{MTPA}

For the MTPA control, the following equations are used (Tang, 1997):

$$
\left\{\begin{array}{l}
\frac{\partial\left(T_{\mathrm{e}} / i_{\mathrm{s}}\right)}{\partial i_{d}}=0 \\
\frac{\partial\left(T_{\mathrm{e}} / i_{\mathrm{s}}\right)}{\partial i_{q}}=0 .
\end{array}\right.
$$

Keeping stator current $i_{\mathrm{s}}$ constant, and substituting $i_{\mathrm{s}}=\sqrt{i_{d}^{2}+i_{q}^{2}}$ into Eq. (12), $i_{d}$ can be written as

$$
i_{d}=\frac{-\psi_{\mathrm{m}}+\sqrt{\psi_{\mathrm{m}}^{2}+4\left(L_{d}-L_{q}\right)^{2} i_{q}^{2}}}{2\left(L_{d}-L_{q}\right)}
$$

and then the torque can be rewritten as

$$
T_{\mathrm{e}}=\frac{3}{4} p i_{q}\left(\sqrt{\psi_{\mathrm{m}}^{2}+4\left(L_{d}-L_{q}\right)^{2} i_{q}^{2}}+\psi_{\mathrm{m}}\right) .
$$
found.

For any given torque, the minimum $i_{d}, i_{q}$ can be

\subsection{Combine DRM and Simulink model}

1. Traction system model with $i_{d}=0$

Fig. 7 shows the PMSM traction system diagram with $i_{d}=0$. The $i_{d}$ reference is set to zero. $i_{q}$ will be controlled by the proportional integral (PI) controlled according to the speed error. The PMSM model is built using an S-function and $L_{d}, L_{q}$ vary with the rotor position.

2. Traction system model with MTPA

PMSM traction system with MTPA control is similar to that with the $i_{d}=0$ control. The only difference is that $i_{d}, i_{q}$ will be calculated according to the torque demand using Eq. (14) as shown in Fig. 8. It can be seen from the equation that the torque and current relationship cannot be solved directly. In this study, an MTPA control block using the S-function will be built to determine $i_{q}$ using a bi-section method for the numeric solution. Then $i_{d}$ can be found.

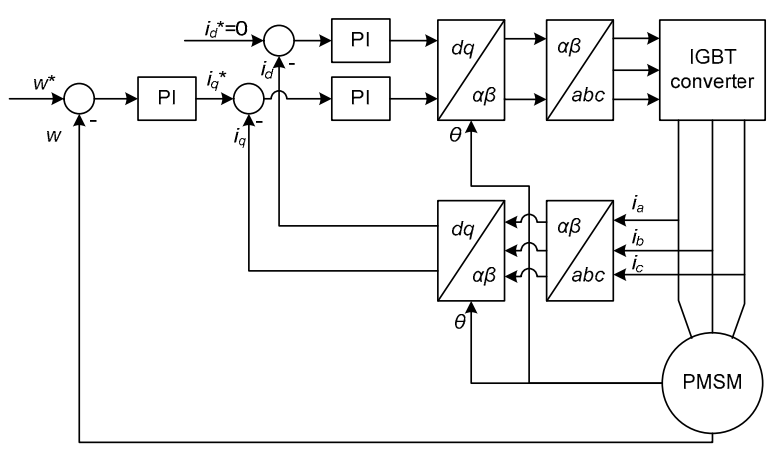

Fig. 7 PMSM traction system diagram with $i_{d}=0$

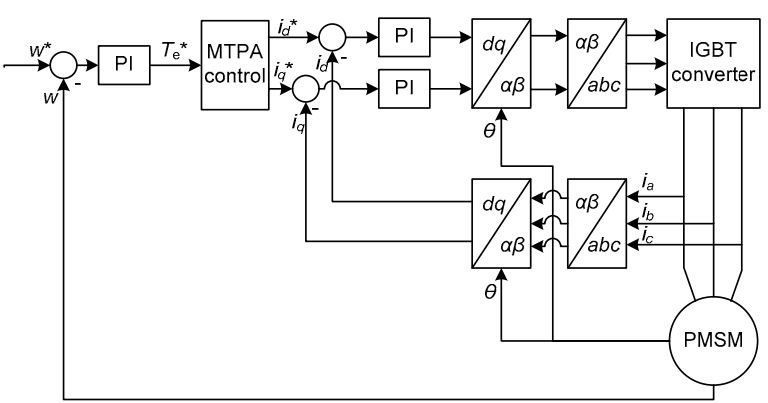

Fig. 8 PMSM traction system diagram with MTPA

\section{Simulation results}

A $600 \mathrm{~kW}$ PMSM traction system model for a high speed train was built. The required starting torque is $3500 \mathrm{~N} \cdot \mathrm{m}$. In the constant torque area, the rated torque is $1350 \mathrm{~N} \cdot \mathrm{m}$ and the speed is $3000 \mathrm{r} / \mathrm{min}$. In the brake mode, the speed will reduce to zero. The output current and torque were observed.

\subsection{Constant parameter PMSM traction system Simulink models}

The first model had $i_{\mathrm{d}}=0$ using Simulink built in blocks. Both $i_{d}=0$ and MTPA control were adopted. 
The motor dynamic speed response, torque, $i_{d}, i_{q}$, and power factor were compared under both control strategies, as shown in Fig. 9.

The speed response is faster and smoother under the MTPA control as shown in Fig. 9a. It also can be seen from Fig. 9b, under both control methods, that the output torque can be controlled precisely, providing starting and braking torque of $3500 \mathrm{~N} \cdot \mathrm{m}$. However, with $i_{d}=0$ control, the torque pulsation was greater than that under MTPA control. It means that the system has better transient performance under MTPA control. For the phase- $A$ current, as shown in Fig. 9c, for the same torque, with MTPA control the current is much less than with $i_{d}=0$ control, which will lead to high efficiency of the PMSM. $i_{d}$ could be less than zero to realize field weakening control under MTPA control as shown in Figs. 9d and 9e. In this case, the operation speed range can be extended. The power factor with MTPA control was better as shown in Fig. 9f.

Based upon the above simulation results, it can be concluded that although the MTPA are more complicated, they have advantages in terms of fast transient behavior, high efficiency, and high power factor.
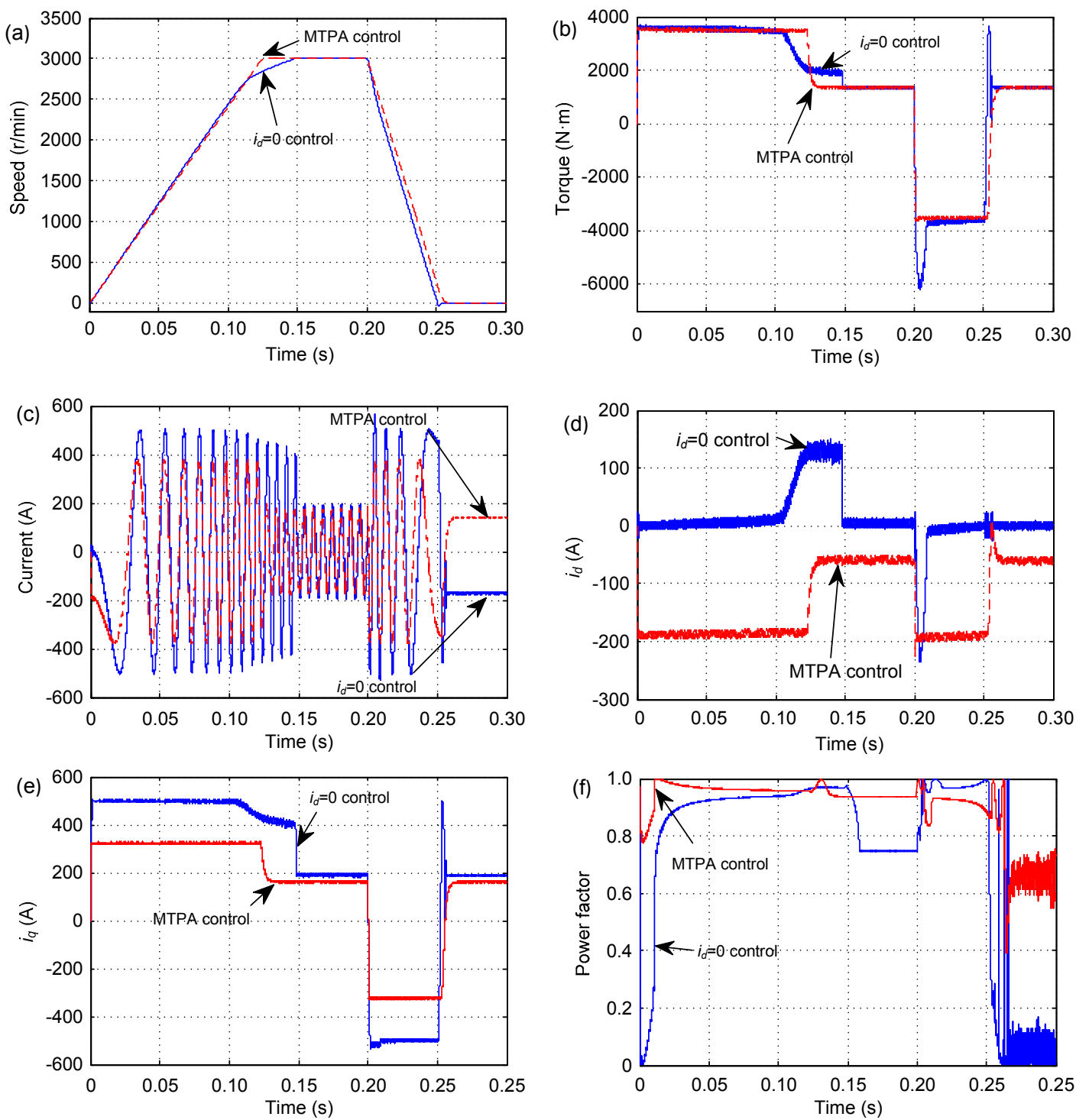

Fig. 9 Comparison of system behavior under $i_{d}=0$ and MTPA control using Simulink model (a) Speed response; (b) Torque; (c) Phase- $A$ current; (d) $i_{d}$; (e) $i_{q}$; (f) Power factor 


\subsection{Combined simulation using DRM and} Simulink

The key feature of the combined simulation using DRM and Simulink is that $L_{d}$ and $L_{q}$ vary with the rotor position. However, the changes of $L_{d}$ and $L_{q}$ will
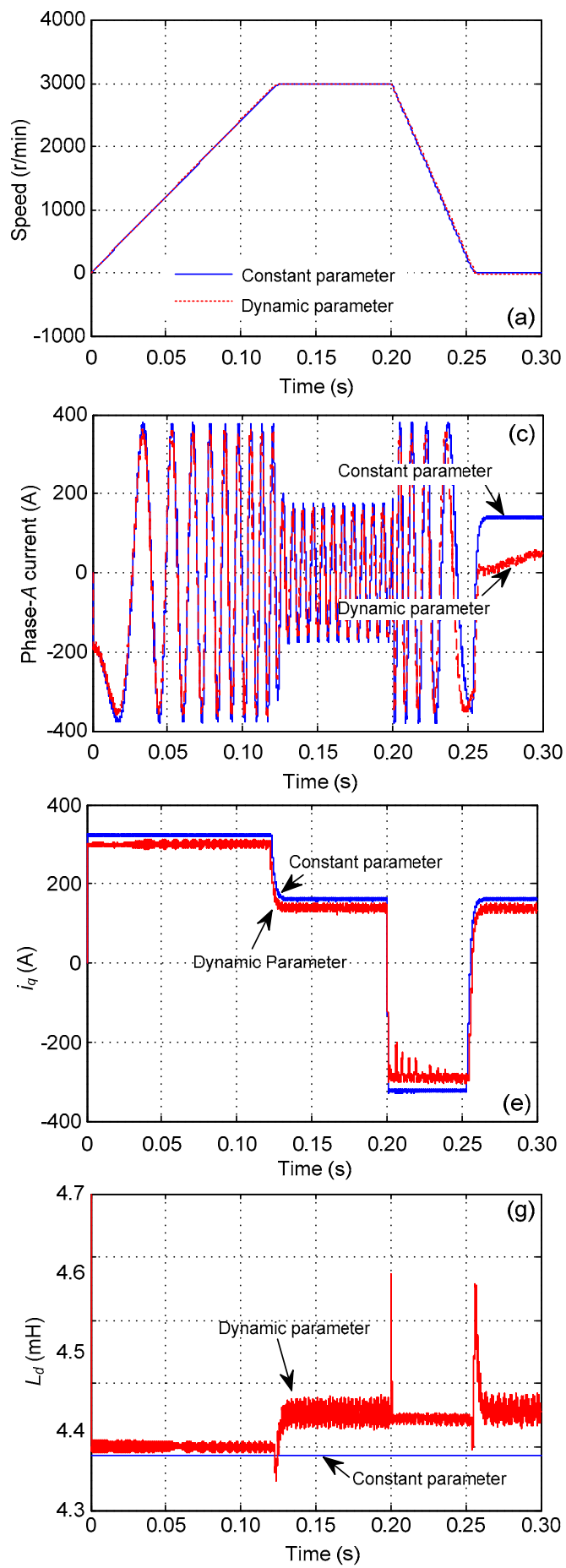

not have much effect under $i_{d}=0$ control. Thus, the system performance under $i_{d}=0$ control will not be investigated in this study. The transient behavior using CPM and combined DPM under MTPA control will be compared. The simulations were carried out. The results are shown in Fig. 10.
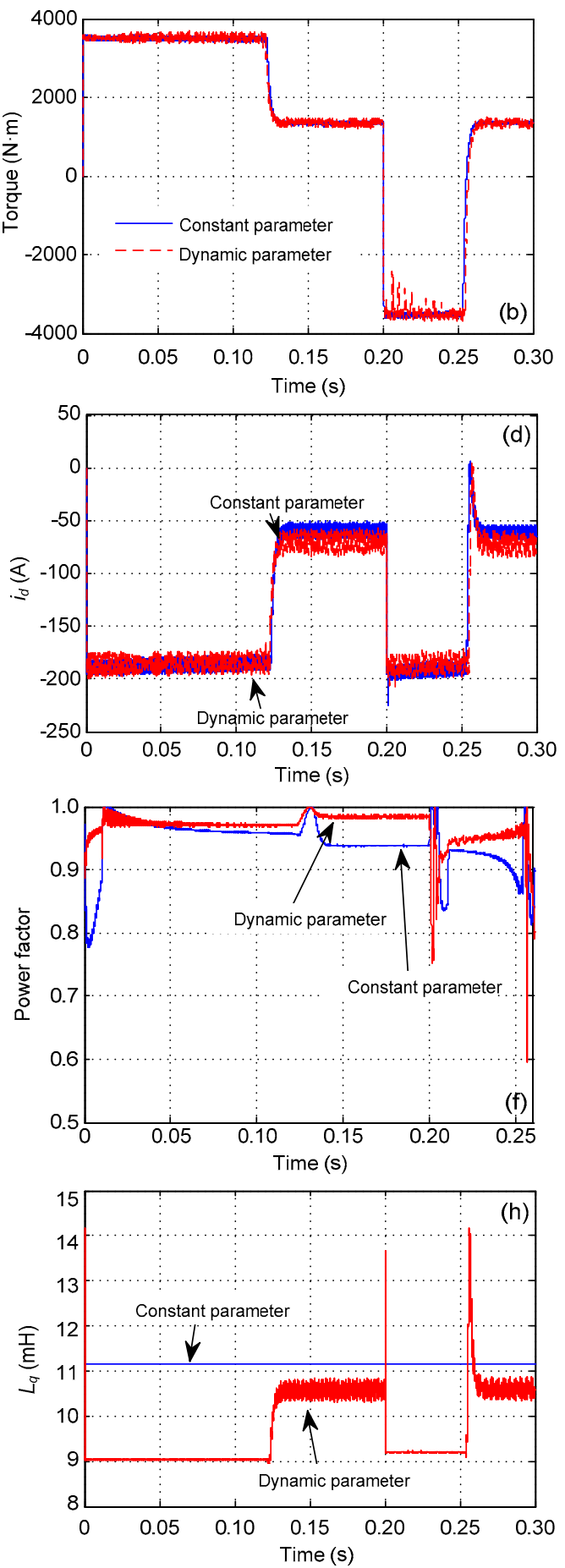

Fig. 10 Comparison of simulations using constant parameter model and dynamic parameters model under MTPA control (a) Speed response; (b) Torque; (c) Phase current; (d) $i_{d}$; (e) $i_{q}$; (f) Power factor; (g) $L_{d}$; (h) $L_{q}$ 
The transient behavior of the system under each model is similar except for the $L_{d}$ and $L_{q}$ as shown in Fig. 10. However, during the acceleration of the train, the system was operating in the constant torque area, and the output torque waveform is as shown in Fig. 11. Because of the variation of $i_{d}$ and $i_{q}$, the degree of motor saturation varied and therefore $L_{d}$ and $L_{q}$ varied. The output torque varied accordingly, especially when the speed was further increased, and the torque pulsation increased correspondingly.

During the braking operation, the output torque waveforms using the CPM and DPM are shown in Fig. 12. The system was in the field weakening operation, therefore $L_{d}$ and $L_{q}$ varied dramatically due to saturation, which leads to a large torque pulsation.
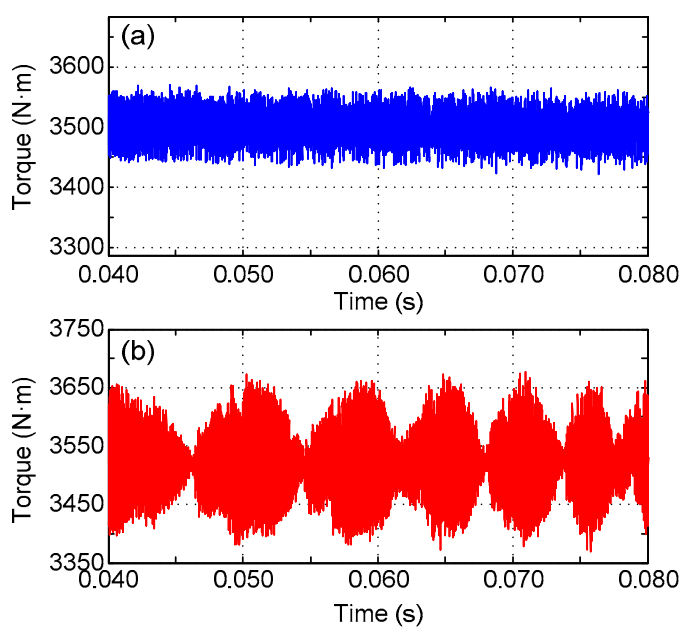

Fig. 11 Output torque under speed accelerating operation: (a) CPM; (b) DPM
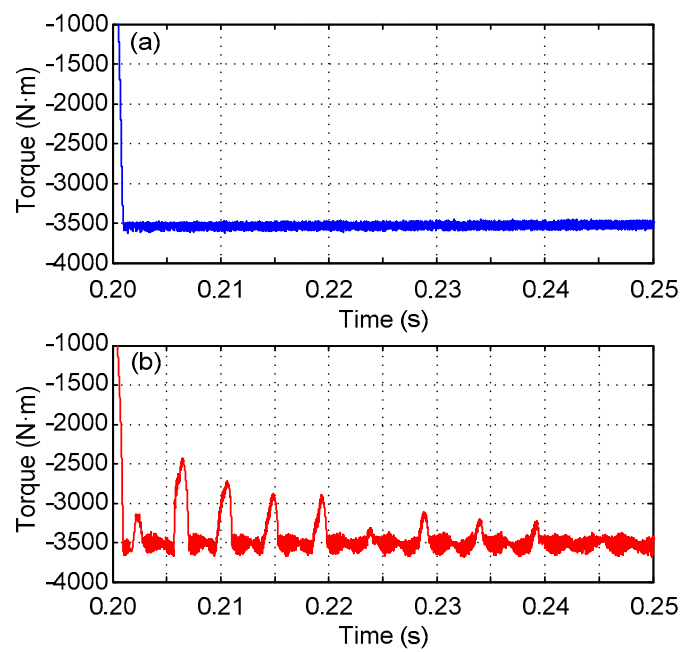

Fig. 12 Comparison of output torque during the braking operation: (a) CPM; (b) DPM

\section{Conclusions}

This paper presented a combined dynamic parameter PMSM traction system model using the DRM and MATLAB-Simulink. Models under $i_{d}=0$ and MTPA control were built. Simulations were carried out under real high speed train operation including acceleration, constant speed, and braking. The results proved that the system with MTPA control has advantages in terms of fast transient response, and high power factor and efficiency. Simulations using both CPM and DPM models were carried out. The results confirm that the DPM model provides higher accuracy without much sacrifice of time consumption or computation resource. The combined DPM model was shown to be useful and able to provide a reference for the actual design and production of a high speed train traction system.

\section{References}

Araujo, D.M., Coulomb, J.L., Chadebec, O., et al., 2014. A hybrid boundary element method-reluctance network method for open boundary 3-d nonlinear problems. IEEE Transactions on Magnetics, 50(2):77-80. [doi:10.1109/ TMAG.2013.2281759]

Carpenter, C.J., 1968. Magnetic equivalent circuits. Proceedings of the Institution of Electrical Engineers, 115(10): 1503-1511.

Dogan, H., Garbuio, L., Nguyen-Xuan, H., et al., 2013. Multistatic reluctance network modeling for the design of permanent-magnet synchronous machines. IEEE Transactions on Magnetics, 49(5):2347-2350. [doi:10.1109/ TMAG.2013.2243426]

Lee, K.K., 2012. The evolution and outlook of core technologies for high-speed railway in China. 1st International Workshop on High-speed and Intercity Railways, 2:495-507. [doi:10.1007/978-3-642-27963-8_45]

Lu, Q.F., Wang, B., Huang, X.Y., et al., 2011. Simulation software for $\mathrm{CRH} 2$ and $\mathrm{CRH} 3$ traction driver systems based on Simulink and VC. Journal of Zhejiang University-SCIENCE A (Applied Physics \& Engineering), 12(12):945-949. [doi:10.1631/jzus.A11GT006]

Matsuoka, K., 2007. Development trend of the permanent magnet synchronous motor for railway traction. IEEJ Transactions on Electrical and Electronic Engineering, 2(2):154-161. [doi:10.1002/tee.20121]

Mermet-Guyennet, M., 2010. New power technologies for traction drives. International Symposium on Power Electronics, Electrical Drives, Automation and Motion, Pisa, Italy, p.719-723.

Nguyen-Xuan, H., Dogan, H., Perez, S., et al., 2014. Efficient reluctance network formulation for electrical machine 
design using optimization. IEEE Transactions on Magnetics, 50(2):869-872. [doi:10.1109/TMAG.2013. 2282407]

Ostovic, V., 1986. A method for evaluation of transient and steady state performance in saturated squirrel cage induction machines. IEEE Transactions on Energy Conversion, 1(3):190-197.

Ostovic, V., 1988. A simplified approach to magnetic equivalent-circuit modeling of induction machines. IEEE Transactions on Industry Applications, 24(2):308-316.

Ostovic, V., 1989. A novel method for evaluation of transient states in saturated electric machines. IEEE Transactions on Industry Applications, 25(1):96-100.

Sewell, P., Bradley, K.J., Clare, J.C., et al., 1999. Efficient dynamic models for induction machines. International Journal of Numerical Modelling: Electronic networks, devices and fields, 12(6):449-464. [doi:10.1002/(sici) 1099-1204(199911/12)12:6<449::aid-jnm365>3.0.co;2W]

Tang, R.Y., 1997. Modern Permanent Magnet Machines: Theory and Design. China Machine Press, Beijing, China, p.473 (in Chinese).

Ugalde, G., Almandoz, G., Poza, J., et al., 2009. Computation of iron losses in permanent magnet machines by multi-domain simulations. 13th European Conference on
Power Electronics and Applications, Barcelona, p.1-10. Wang, X.H., 2011. Permanent Magnet Machines. China Electric Power Press, Beijing, China, p.327 (in Chinese).

Yao, L., 2006. Magnetic Field Modelling of Machine and Multiple Machine Systems Using Dynamic Reluctance Mesh Modelling. PhD Thesis, University of Nottingham, Nottingham, UK.

\section{中文概要}

题 目: 基于动态磁网络和 Simulink 的高速铁路牵引传动 系统联合仿真

目 的: 提出基于动态磁网络和 Simulink 的高速铁路牵引 传动系统的动态参数模型, 提高高速铁路牵引传 动系统仿真分析的准确度。

方 法: 将动态磁网络计算得出的动态参数 $L_{d}, L_{q}$ 等以查 表的形式嵌入 Simulink 模型, 有效地实现动态 参数。

结 论: 该动态参数模型能在不显著增加仿真运算量和仿 真时间的条件下有效地提高计算的准确度。

关键词: 高速铁路牵引传动系统; 永磁电机; 动态参数模 型; 动态磁网络; Simulink 